\title{
HIDROLISIS MINYAK JARAK PAGAR MENJADI ASAM LEMAH BEBAS MENGGUNAKAN KATALIS CaO
}

\author{
Abdulloh Abdulloh $^{1 *}$, Alfa Akustia Widati ${ }^{1}$, Faiz Tamamy ${ }^{1}$ \\ ${ }^{1}$ Departemen Kimia Fakultas Sains dan Teknologi \\ Universitas Airlangga \\ *email:abdulloh@.fst.unair.ac.id,doelabd71@gmail.com
}

\begin{abstract}
Abstrak
Telah dilakukan hidrolisis minyak jarak pagar (Jatropha curcas oil: JO) menggunakan katalis $\mathrm{CaO}$. Reaksi ini dimaksudkan untuk meningkatkan nilai ekonomis minyak jarak pagar selain biodiesel. Katalis $\mathrm{CaO}$ dikalsinasi terlebih dahulu pada suhu $800^{\circ} \mathrm{C}$ untuk menghindari terjadinya deaktivasi katalis oleh terbentuknya $\mathrm{CaCO}_{3}$. Pada penelitian ini dilakukan karakterisasi katalis $\mathrm{CaO}$ meliputi struktur kristal $\mathrm{CaO}$, luas permukaan, jumlah situs basa dan kekuatan kebasaan serta aktivitas katalitiknya. Hasil penelitian menunjukkan, katalis $\mathrm{CaO}$ memiliki luas permukaan $26,45 \mathrm{~m}^{2} / \mathrm{g}$, kekuatan situs basa $\left(\mathrm{pK}_{\mathrm{B}}\right)$ pada daerah $7,2<\mathrm{pK}_{\mathrm{BH}} \mathrm{CaO}<15,0$. Hasil uji aktivitas katalis $\mathrm{CaO}$ pada reaksi hidrolisis $\mathrm{CJO}$ diperoleh konversi CJO menjadi asam lemak bebas (free fatty acid: FFA) sebesar 77,58\% pada waktu 60 menit.
\end{abstract}

Kata kunci: hidrolisis, minyak jarak pagar (JO), free fatty acid (FFA), CaO dan situs basa

\begin{abstract}
Hydrolysis of Jatropha curcas oil has been carried out using $\mathrm{CaO}$ as a catalyst. This reaction is intended to increase the economic value besides biodiesel. $\mathrm{CaO}$ catalyst was calcined at a temperature of $800{ }^{\circ} \mathrm{C}$ to avoid catalyst deactivation by formation of $\mathrm{CaCO}_{3}$. In this research include the characterization of catalysts $\mathrm{CaO}$ crystal structure, surface area, the number of base sites and the strength of basicity and catalytic activity. The results of the analysis showed that $\mathrm{CaO}$ catalyst has a surface area of $26.45 \mathrm{~m}^{2} / \mathrm{g}$, the number of base sites of $221.77 \mathrm{mmol} / \mathrm{g}$ and the strength of base sites $\left(\mathrm{pK}_{\mathrm{BH}}\right)$ in the range of $7.2<\mathrm{pK} \mathrm{BH}_{\mathrm{BaO}}<$ 15.0. From catalytic activity test showed that that the use of the catalytic activity of $\mathrm{CaO}$ catalyst in the hydrolysis reaction CJO into free fatty acids (FFA) as much as $77.58 \%$ for 60 minutes.
\end{abstract}

Keywords: hydrolysis, Jatropha curcas oil (JO), free fatty acid (FFA), CaO and base site

\section{Pendahuluan}

Jarak pagar (Jatropha curcas Linnaeus) merupakan tumbuhan semak berkayu yang banyak ditemukan di daerah tropis. Tumbuhan ini dikenal sangat tahan kekeringan dan mudah diperbanyak dengan stek. Jarak pagar juga dikenal sebagai tanaman obat. Saat ini, jarak pagar dimanfaatkan sebagai sumber bahan bakar hayati untuk mesin diesel. Pada tahun
2005, tanaman jarak pagar banyak dikembangkan di Indonesia. Minyak jarak pagar kasar atau disebut juga crude jatropha oil (CJO) banyak digunakan di industri farmasi, pelumas, cat, vernis, tinta cetak, tekstil, otomotif, logam dan karet. Minyak jarak pagar mulai menjadi sorotan dunia semenjak melonjaknya harga bahan bakar minyak. Kandungan minyak yang terdapat dalam biji baik cangkang maupun 
buah jarak pagar berkisar $25-35 \%$ berat kering biji (Prihandana dan Hendroko, 2007). Akan tetapi, di dalam minyak jarak pagar terkandung racun antara lain zat kursin (curcin) dan ester forbol yang membuat minyak jarak pagar tidak dapat digunakan sebagai minyak makan. Tanaman jarak kemudian menjadi pilihan utama untuk digunakan sebagai bahan bakar alternatif biodiesel karena tidak bersaing dengan produk pangan, seperti minyak kelapa dan CPO (crude palm oil) (Kompas, 15/07/06).

Di Indonesia, penelitian biodiesel dirintis oleh Lemigas dan Pertamina yang mencampur biodiesel dan solar dengan rasio 30:70 untuk kendaraan bermesin diesel komersial (Kompas, 19/07/05). Namun, timbul beberapa masalah terkait pengembangan minyak jarak sebagai bahan bakar alternatif yaitu, nilai viskositas dan titik nyala (flash point) minyak jarak yang masih cukup tinggi. Nilai viskositas minyak jarak kasar sebesar $24,5 \mathrm{~mm}^{2} \mathrm{~s}^{-1}$ pada suhu $15^{\circ} \mathrm{C}$ dan titik nyalanya sebesar $225^{\circ} \mathrm{C}$. Nilai ini masih lebih tinggi dibandingkan minyak diesel yang hanya mempunyai viskositas sebesar $2,60 \mathrm{~mm}^{2} \mathrm{~s}^{-1}$ dan titik nyala $68^{\circ} \mathrm{C}$ (Tiwari et al., 2007). Salah satu usaha untuk meningkatkan nilai ekonomis minyak jarak pagar adalah menghidrolisis minyak jarak pagar menjadi asam lemaknya sehingga asam lemak yang terkandung di dalam minyak jarak pagar bisa dimanfaatkan lebih lanjut. Asam lemak penyusun minyak jarak pagar terdiri atas $22,7 \%$ asam jenuh dan $77,3 \%$ asam tak jenuh.

Selama ini, reaksi hidrolisis minyak menggunakan katalis homogen, misalnya $\mathrm{KOH}, \mathrm{NaOH}$ dan lain sebagainya. Katalis homogen berada dalam satu fasa dengan reaktan. Hal ini menyebabkan molekul katalis dan reaktan dapat berinteraksi dengan mudah sehingga reaksi mudah berlangsung. Akan tetapi proses pemisahan katalis dengan produk lebih sulit dibandingkan dengan katalis heterogen. Pada skala industri penggunaan katalis heterogen lebih disukai karena lebih ramah lingkungan, tidak membutuhkan proses netralisasi katalis dan reaksi dapat dilakukan dengan metode bed katalis sehingga biaya produksi lebih murah dibandingkan dengan penggunaan katalis homogen. Salah satu katalis heterogen basa yang saat ini banyak digunakan adalah $\mathrm{CaO}$.

\section{Metode Penelitian}

Alat dan Bahan

Alat-alat yang digunakan dalam penelitian ini terdiri dari difraktometer sinar-X Phillip, surface area analyzer gas sorption analyzer NOVA-1000, Quantachrome Corp, hot plate, krus porselen, mortar agat, ayakan dengan ukuran 200 mesh, rotavapor, furnace, oven, pengaduk magnetik, neraca analitik Ohaus PAJ603, seperangkat refluks, termometer, corong pisah, labu leher tiga, stirer, labu destilasi, erlenmeyer, dan alatalat gelas yang lazim digunakan pada laboratorium. Sedangkan bahan-bahan yang digunakan dalam penelitian ini adalah $\mathrm{CaO}$ (Merck, 99\%), asam oksalat (Merck, 99,5\%), minyak jarak pagar dari PTPN-XII Jember, air, asam sulfat (Merck, 98\%), kalium hidroksida (Merck, $85 \%$ ), indikator phenolptalein (Merck), nheksana Univar, (teknis), etanol (Merck, 96\%), toluena (Merck, 99,5\%), asam oksalat (Merck, 99,5\%), bromothymol blue (Merck, 99,5\%), phenolphthalein (Aldrich, 99\%), 2,4-dinitro-aniline (Aldrich, 98\%), 4-nitroaniline (Aldrich, 99\%)

\section{Prosedur Penelitian}

Sebelum reaksi hidrolisis dilakukan, $2 \mathrm{~g}$ $\mathrm{CaO}$ dikalsinasi selama 4 jam pada suhu $800^{\circ} \mathrm{C}$ untuk menghilangkan gas $\mathrm{CO}_{2}$ dan $\mathrm{H}_{2} \mathrm{O}$ yang teradsorpsi pada permukaan $\mathrm{CaO}$. Selanjutnya $\mathrm{CaO}$ didinginkan dalam desikator. Untuk uji karakteristik katalis $\mathrm{CaO}$ meliputi luas permukaan menggunakan peralatan surface area analyzer gas sorption analyzer dengan metode BJH (Barrett Joyner-Halenda), 
analisis $X$-Ray Diffraction. Adapun untuk menentukan kekuatan basa, kedalam 4 buah labu Erlenmeyer dimasukkan $0,05 \mathrm{~g}$ katalis $\mathrm{CaO}, 5 \mathrm{~mL}$ toluena dan 2-3 tetes indikator pada setiap labu Erlenmeyer, yaitu bromothymol blue $(\mathrm{p} K \mathrm{BH}=7.2)$, phenolphthalein $(\mathrm{p} K \mathrm{BH}=9.3), 2$,4-dinitroaniline $(\mathrm{p} K \mathrm{BH}=15.0)$ dan 4-nitroaniline $(\mathrm{p} K \mathrm{BH}=18.4)$. Dari keempat indikator tersebut, yang memberikan perubahan warna merupakan rentang kekuatan basa.

Untuk keperluan uji aktivitas katalis dimasukkan $10 \mathrm{~g} \mathrm{JO}, 2 \mathrm{~g} \mathrm{CaO}$ dan $100 \mathrm{~mL}$ etanol $20 \%$ ke dalam labu reaksi leher tiga kemudian direfluks dengan variasi waktu selama $15 ; 30 ; 45 ; 60 ; 90 ; 120 ; 150 ; 180$ menit sambil diaduk dengan pengaduk magnetik. Untuk memisahkan, FFA, katalis dan gliserol setelah reaksi ditambahkan $100 \mathrm{~mL} \mathrm{H}_{2} \mathrm{SO}_{4} \quad 10 \%$ untuk mengendapkan $\mathrm{Ca}(\mathrm{OH})_{2}$ yang berasal dari $\mathrm{CaO}$ sebagai $\mathrm{CaSO}_{4}$. Aktivitas katalitik ditentukan dari perubahan FFA antara sebelum $\left(\mathrm{FFA}_{\mathrm{o}}\right)$ dan sesudah $\left(\mathrm{FFA}_{t}\right)$ reaksi hidrolisis yang nilainya ditentukan berdasarkan bilangan asam (AV), sesuai persamaan 1 dan 2 .

$$
\begin{array}{r}
\text { Konversi }=\frac{F F A_{t}-F F A_{o}}{100 \%-F F A_{o}} \\
F F A=\frac{A V}{2} \times 100 \%
\end{array}
$$

\section{Hasil dan Pembahasan}

\section{Karakteristik Katalis $\mathrm{CaO}$}

Dari hasil analisis difraktogram $\mathrm{CaO}$ sebelum dan sesudah dikalsinasi (Gambar 1) menunjukkan beberapa perbedaan intensitas puncak, yaitu pada sudut $2 \theta$ $29,4^{\circ}, 32,2^{\circ}, 34,1^{\circ}, 37,3^{\circ}$ dan $47,1^{\circ}$. Intesitas puncak pada sudut $2 \theta 29,4^{\circ}$ adalah puncak khas $\mathrm{CaCO}_{3}$, pada sudut $2 \theta$ $32,2^{\circ}$ dan $37,3^{\circ}$ adalah puncak khas $\mathrm{CaO}$ (Nakatani et al., 2009) dan pada sudut $2 \theta$ $34,1^{\circ}$ dan $47,1^{\circ}$ adalah puncak khas $\mathrm{Ca}(\mathrm{OH})_{2}$ (Ngamcharussrivichai et al., 2010) Perbedaan ini menunjukkan, bahwa jumlah $\mathrm{CaO}$ bertambah dan jumlah $\mathrm{CaCO}_{3}$ dan $\mathrm{Ca}(\mathrm{OH})_{2}$ berkurang setelah proses kalsinasi.

Proses kalsinasi katalis $\mathrm{CaO}$ juga menyebabkan perubahan dari material non pori menjadi material berpori. Hal ini ditunjukkan oleh adanya perubahan kurva adsorpsi-desorpsi isoterm gas $\mathrm{N}_{2}$ (Gambar 2 dan 3). Perubahan tersebut juga menyebabkan volume pori bertambah dari 0,015 menjadi $0,234 \mathrm{~cm}^{3} / \mathrm{g}$ dan luas permukaan bertambah dari 2,065 menjadi $26,451 \mathrm{~m}^{2} / \mathrm{g}$ (Tabel 1). Pertambahan volume pori dan luas permukaan $\mathrm{CaO}$ disebabkan oleh desorpsi molekul-molekul gas $\mathrm{CO}_{2}$ dan $\mathrm{H}_{2} \mathrm{O}$ dari permukaan $\mathrm{CaO}$ sesuai reaksi pada persamaan 3 dan 4 .

$$
\begin{aligned}
& \mathrm{CaCO}_{3(s)} \stackrel{800^{\circ} \mathrm{C}}{\longrightarrow} \mathrm{CaO}_{(\mathrm{s})}+\mathrm{CO}_{(\mathrm{g})} \\
& \mathrm{Ca}(\mathrm{OH})_{2(\mathrm{~s})} \longrightarrow \mathrm{CaO}_{(s)}+\mathrm{H}_{2} \mathrm{O}_{(g)}
\end{aligned}
$$

Tabel 1. Luas permukaan dan volume pori $\mathrm{CaO}$ sebelum (a) dan sesudah (b) dikalsinasi

\begin{tabular}{ccc}
\hline Sampel & $\begin{array}{c}\text { Luas Permukaan } \\
\left(\mathrm{m}^{2} / \mathrm{g}\right)\end{array}$ & $\begin{array}{c}\text { Volume Pori } \\
\left(\mathrm{cm}^{3} / \mathrm{g}\right)\end{array}$ \\
\hline $\mathrm{CaO}(\mathrm{a})$ & 2,065 & 0,015 \\
$\mathrm{CaO}(\mathrm{b})$ & 26,451 & 0,234 \\
\hline
\end{tabular}

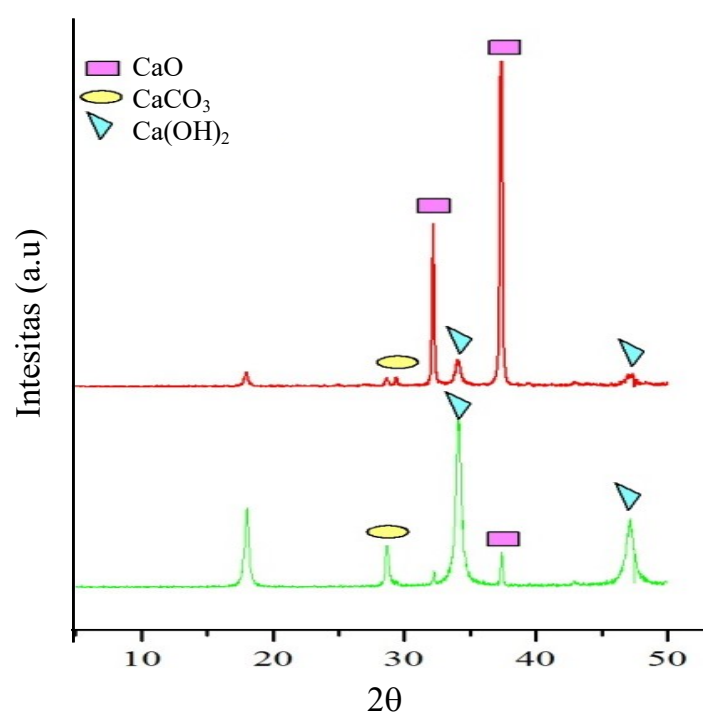

Gambar 1. Difraktogram $\mathrm{CaO}$ sebelum (a) dan sesudah (b) dikalsinasi 
Dari hasil pengamatan perubahan warna indikator (bromothymol biru, phenolphthalein, 2,4-dinitroanilin dan 4nitroanilin) yang diteteskan kedalam labu Erlemnyer yang mengandung $\mathrm{CaO}$, hanya indikator bromothymol biru dan 2,4dinitroanilin yang menunjukkan perubahan warna indikator. Bromothymol biru mengalami perubahan warna dari tidak berwarna menjadi biru dan 2,4dinitroanilin dari tidak berwarna menjadi berwarna kuning. Hal ini menunjukkan bahwa kekuatan situs basa $\left(\mathrm{pK}_{\mathrm{BH}}\right) \mathrm{CaO}$ berada dalam rentang 7,2 $<\mathrm{pK}_{\mathrm{BH}} \mathrm{CaO}<$ 15.

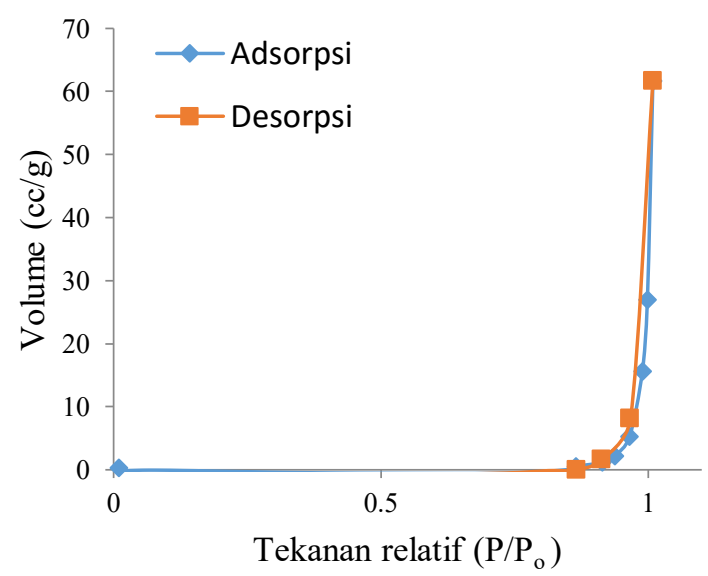

Gambar 2. Adsorpsi-desorpsi Isoterm gas $\mathrm{N}_{2}$ pada $\mathrm{CaO}$ sebelum dikalsinasi

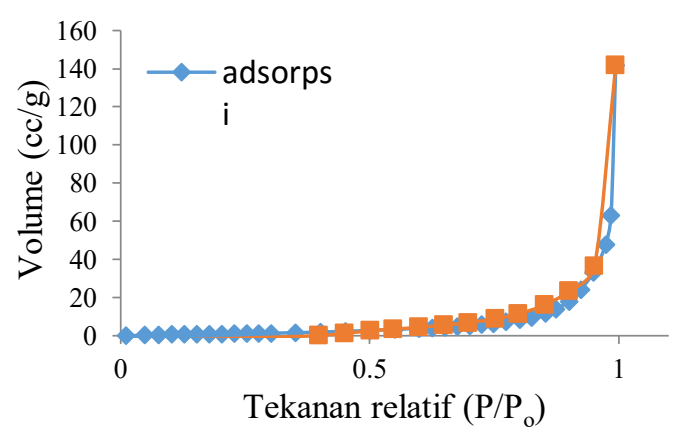

Gambar 3. Adsorpsi-desorpsi isoterm gas $\mathrm{N}_{2}$ pada $\mathrm{CaO}$ sesudah dikalsinasi

Aktivitas Katalis CaO pada Hidrolisis JO

Mekanisme reaksi pembentukan FFA melalui hidrolisis minyak jarak pagar menggunakan katalis $\mathrm{CaO}$ hampir sama dengan mekanisme reaksi pada pemakaian katalis $\mathrm{CaO}$ pada reaksi transesterifikasi minyak (trigliserida: TG) dengan metanol menjadi biodiesel. Pada mekanisme reaksi transesterifikasi, reaksi diawali oleh proses adsorpsi metanol pada permukaan katalis $\mathrm{CaO}$ pada tahap 1, kemudian diikuti oleh reaksi tahap 2 yaitu pembentukan biodiesel dan digliserida (DG). Reaksi tahap 2 berlangsung kembali sampai diperoleh gliserol (Kouzu et al., 2008). Berdasarkan mekanisme tersebut maka mekanisme reaksi hidrolisis minyak jarak pagar adalah sebagai berikut (Gambar 4):

1. Tahap 1 adalah reaksi adsorpsi air pada permukaan katalis $\mathrm{CaO}$

2. Tahap 2 adalah reaksi transesterifikasi TG menjadi FFA dan DG pada permukaan katalis $\mathrm{CaO}$

3. Tahap 3 adalah reaksi transesterifikasi DG menjadi FFA dan MG pada permukaan katalis $\mathrm{CaO}$

4. transesterifikasi MG menjadi FFA dan gliserol pada permukaan katalis $\mathrm{CaO}$

Dari hasil pengamatan menunjukkan bahwa jumlah FFA semakin bertambah dari $11,36 \%$ menjadi $24,07 \%$ saat 15 menit dan $77,37 \%$ saat 45 menit (Tabel 2). Tabel 2 juga ditunjukkan bahwa aktivitas katalis $\mathrm{CaO}$ bertambah besar dari 0 menjadi 0,96 saat 15 menit, 1,20 saat 30 menit dan 1,68 saat 45 menit. Peningkatan aktivitas katalis tersebut disebabkan oleh adanya terbentuknya kompleks $\mathrm{CaO}$-gliserin selama reaksi berlangsung yang dapat meningkatkan aktivitas katalis $\mathrm{CaO}$ (Kawashima et al., 2009). ktivitas katalis $\mathrm{CaO}$ mulai berkurang dari 1,68 menjadi 1,29 saat 60 menit, 0,82 saat 90 menit dan seterusnya (Tabel 2). Hal ini disebabkan karena katalis $\mathrm{CaO}$ mengalami pengikisan sebagai akibat dari reaksi $\mathrm{CaO}$ dengan FFA (Kouzu et al., 2008) membentuk sabun sehingga jumlah adsorpsi $\mathrm{H}_{2} \mathrm{O}$ pada permukaan katalis menjadi berkurang. Adanya reaksi FFA dengan katalis $\mathrm{CaO}$ pada reaksi hidrolisis pada penelitian ini ditunjukkan oleh adanya penurunan jumlah konversi dan fluktuasi jumlah FFA setelah mencapai konversi maksimum, yaitu $77,58 \%$ saat reaksi berlangsung 60 menit. 

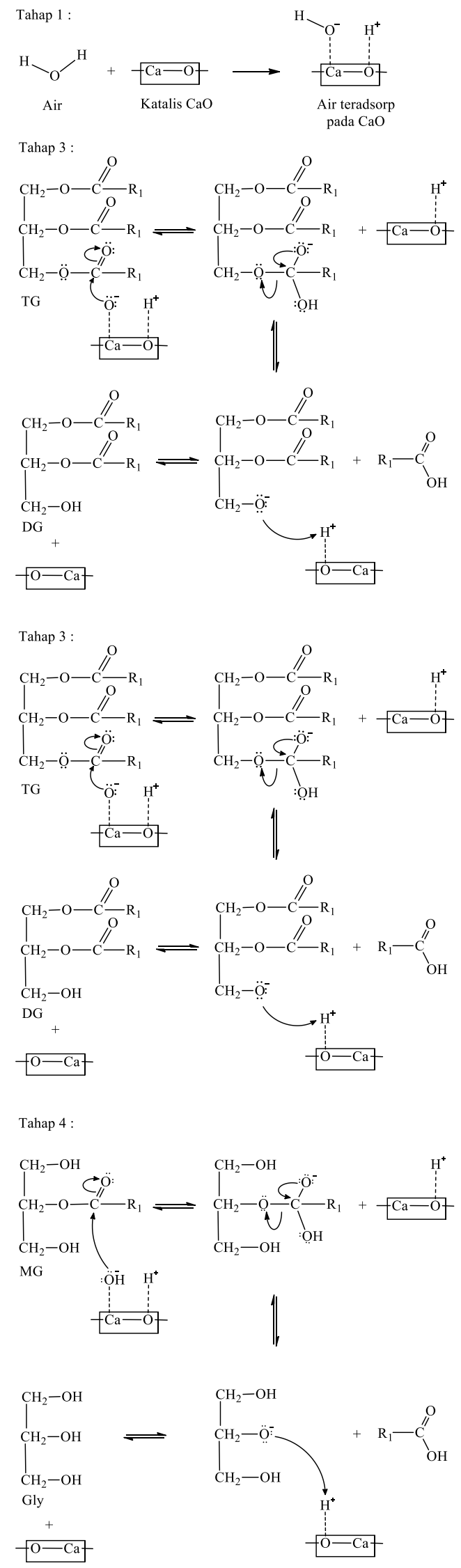

Gambar 4. Mekanisme reaksi hidrolisis minyak jarak pagar dengan katalis $\mathrm{CaO}$
Tabel 2. Jumlah FFA dan aktivitas katalis $\mathrm{CaO}$ pada reaksi hidrolisis $\mathrm{JO}$

\begin{tabular}{cccc}
\hline $\begin{array}{c}\text { Waktu } \\
\text { (menit) }\end{array}$ & $\begin{array}{c}\text { FFA } \\
(\%)\end{array}$ & $\begin{array}{c}\text { Konversi } \\
(\%)\end{array}$ & Aktivitas \\
\hline 0 & 11,36 & 0 & 0 \\
15 & 24,07 & 14,34 & 0,96 \\
30 & 43,27 & 36,00 & 1,20 \\
45 & 78,37 & 75,60 & 1,68 \\
60 & 80,12 & 77,58 & 1,29 \\
90 & 76,59 & 73,59 & 0,82 \\
120 & 76,25 & 73,21 & 0,61 \\
150 & 78,33 & 75,55 & 0,50 \\
180 & 77,86 & 75,03 & 0,42 \\
\hline
\end{tabular}

\section{Kesimpulan}

1. Katalis $\mathrm{CaO}$ yang digunakan untuk reaksi hidrolisis pada penelitian ini memiliki kekuatan situs basa dan luas permukaan berturut-turut $7,2<\mathrm{pK}_{\mathrm{BH}}$ $\mathrm{CaO}<15,0$ dan $26,45 \mathrm{~m}^{2} / \mathrm{g}$.

2. $\mathrm{CaO}$ dapat digunakan sebagai katalis untuk reaksi hidrolisis pada minyak jarak pagar.

3. Aktivitas katalis $\mathrm{CaO}$ pada awal reaksi semakin bertambah besar sampai diperoleh konversi maksimum sebesar $77,58 \%$ saat reaksi berlangsung selama 60 menit tetapi kemudian mengalami penurunan dan fluktuasi.

\section{Daftar Pustaka}

Kawashima, A., Matsubara, K. and Honda, K. (2009). Acceleration of catalytic activity of calcium oxide for biodiesel production, Bioresource Technology, 100, 696-700.

Kouzu, M., Kasuno, T., Tajika, M., Sugimoto, Y., Yamanaka, S. and Hidaka, J. (2008). Calcium oxide as a solid base catalyst for transesterification of soybean oil and its application to biodiesel production, Fuel, 87, 2798-2806.

Tiwari, K. A., Kumar, A. and Raheman, H. (2007). Biodiesel production from jatropha oil (Jatropha curcas) with high free fatty acids: An optimized process, Biomass and Bioenergy, 31, 569-575. 
Nakatani, N., Takamori, H., Takeda, K. and Sakugawa, H. (2009). Transesterification of soybean oil using combusted oyster shell waste as a catalyst, Bioresource Technology, 100, 1510-1513.

Ngamcharussrivichai, C., Nunthasanti, P., Tanachai, S. and Bunyakiat, K. (2010). Biodiesel production through transesterification over natural calciums, Fuel Processing Technology, 91, 1409-1415.

Prihandana, R. dan Hendroko, R. (2007). Energi Hijau Pilihan Bijak Menuju Negeri Mandiri Energi, Penebar Swadaya, Jakarta. 